\title{
Asymptomatic bacteriuria in diabetes mellitus patients in Southwest Cameroon
}

\author{
Marie E. A. Bissong ${ }^{1 *}$, Peter N. Fon ${ }^{2}$, Fritz O. Tabe-Besong ${ }^{3}$ and Theresa N. Akenji1 ${ }^{1}$
}

1. Department of Microbiology and Parasitology, Faculty of Science, University of Buea, Cameroon

2. Department of Public Health, Faculty of Health Sciences, University of Buea, Cameroon

3. Department of Medical Laboratory Sciences, Faculty of Health Sciences, University of Buea, Cameroon

\begin{abstract}
Background: Asymptomatic bacteriuria (ASB) is common in diabetics and predisposes these patients to more severe urinary tract infections (UTIs). Reports on the prevalence and etiology of ASB especially in developing countries appear contradictory.

Objectives: To determine the prevalence and etiology of ASB and antimicrobial resistance of urinary isolates in diabetics and non-diabetics.

Methods: The study involved a total of 265 participants including 154 diabetes mellitus patients and 111 non-diabetics in Southwest Cameroon. Mid-stream urine was collected from consented subjects and each sample tested using the dipstick, microscopy and culture techniques. Isolates were identified using standard biochemical tests.

Results: ASB was detected in $33.2 \%$ of participants; $38.3 \%$ in diabetics and $26.1 \%$ in non-diabetics ( $P=0.03)$. Coagulasenegative staphylococci (CNS) were the predominant organisms (36.3\%) isolated from urine in both diabetics and nondiabetics. Other isolates included Klebsiella sp (15.9\%), Candida sp (13.7\%), E. coli (10.8\%) and Serratia sp (10.8\%). Candida sp was isolated more from diabetics than non-diabetics $(\mathrm{P}=0.01)$. There was no significant difference in resistance between diabetics and non-diabetics $(\mathrm{P}>0.05)$. Most isolates showed multiple resistance and ciprofloxacin was the most active ingredient against bacterial uropathogens.

Conclusion: The study revealed a high prevalence of ASB in diabetics than in non-diabetics. A change in the aetiologic spectrum was observed with Staphylococcus sp accounting for majority of ASB. Most isolates showed multiple resistance in both diabetics and non-diabetics; therefore the need to speed up sensitization against antibiotic abuse in Southwest Cameroon.
\end{abstract}

Keywords: Diabetes mellitus, prevalence, asymptomatic bacteriuria, antimicrobial resistance

African Health Sciences 2013; 13(3): 661 - 666 http://dx.doi.org/10.4314/ahs.v13i3.20

\section{Introduction}

Diabetes has been recently associated with urinary tract infections. ${ }^{1}$ The mechanism of pathogenesis for this association is not fully elucidated, however, it is suggested that high glucose concentration in urine may favour the growth of pathogenic microorganisms. ${ }^{2}$ Asymptomatic bacteriuria is a form of UTI characterized by the presence of significant amount $\left(>10^{5} \mathrm{cfu} / \mathrm{ml}\right)$ of bacteria in urine..$^{3,4}$

Several studies have documented the association of ASB with diabetes; however, reports on the prevalence of ASB appear contradictory.

\begin{tabular}{|l|}
\hline *Corresponding author: \\
Marie Ebob Agbortabot Bissong \\
Department of Microbiology and Parasitology \\
Faculty of Science, University of Buea \\
P. O. Box 63 \\
Buea, Cameroon \\
Tel: +237 75301641 \\
Email: mabissong@yahoo.com \\
\hline
\end{tabular}

Most studies reported the prevalence to be higher in people with diabetes than people without diabetes. ${ }^{5,6,7}$ On the contrary, another study ${ }^{8}$ reported no significant difference in the prevalence of ASB between diabetic women and non-diabetic women $(\mathrm{P}=0.07)$.

In the Netherlands, a prevalence of $26 \%$ among women with diabetes compared to $6 \%$ in non-diabetic women was reported. ${ }^{9}$ ASB was also reported in $13.7 \%$ of diabetic women in Tanzania ${ }^{4}$; $20 \%$ in Iran and $36.2 \%$ in Nigeria. ${ }^{7,10}$ The variations have been attributed to differences in the screening test, geographical region and ethnicity. ${ }^{11}$ The most frequently isolated uropathogens include Escherichia coli, Klebsiella pneumoniae, Streptococcus agalactiae, Enterococcus faecalis, coagulase negative Staphylococcus and Streptococcus pyogenes. ${ }^{3,45}$ Although E. coli is known to be the most common uropathogen, other microorganisms are emerging with predominance in cases of ASB. 
Report from previous study noted a changing pattern of ASB with Klebsiella sp accounting for the majority (42.4\%) of asymptomatic bacteriuria among diabetics. ${ }^{3}$ Another recent study in Nigeria reported Staphylococcus aureus to be the most common uropathogen isolated from both diabetics and non-diabetics with ASB. ${ }^{12}$ Antibiotic resistance of uro-pathogens is increasingly being reported with high occurrence of multiple drug resistant strains. ${ }^{3,5,10}$ Ciprofloxacin has been shown to be effective against most urinary isolates. ${ }^{4,10}$ An increase in the trend of diabetes in Cameroon was postulated some five years ago ${ }^{13}$ and in the same setting, recent studies have reported high resistance to commonly used antibiotics. ${ }^{14,15}$ Although ASB is a major concern in diabetics, there is little information on the occurrence of ASB among diabetics in our local setting. Thus, the current study is aimed at investigating the prevalence and aetiology of ASB and antimicrobial resistant pattern of urinary isolates in diabetic and non-diabetic persons in Southwest Cameroon.

\section{Methods}

A total of 265 participants were enrolled into the study including 154 diabetic patients and 111 non-diabetics. Diabetic patients were enrolled into the study during their regular visits at clinics in three hospitals in Southwest Region, Cameroon. Non-diabetics were healthy individuals recruited from the general population during a free diabetic/ hypertension screening campaign. Criteria for inclusion were age $>18$ years; history of diabetes for diabetics and no diabetes for non-diabetics. Exclusion criteria included pregnancy; history of any underlying illness; signs and symptoms of UTI and antibiotic/antimicotic usage within one week. Diabetic status was further confirmed using IDF standards; diabetes (FBS $>126 \mathrm{mg} / \mathrm{dl}$ and or the use of hypoglycemic drugs). Ethical clearance was obtained from the Regional Delegation for Public Health and the University of Buea Institutional Review Board. A questionnaire was administered to collect demographic and clinical data from participants and specimens were collected only from consented subjects.

The study participants were educated on how to collect a "clean-catch" midstream urine specimen and the importance to avoid contamination. They were advised on washing of hands prior to collection and labia separation, especially in females. Participants who had difficulties collecting their specimens were assisted by trained personnel. Urine samples were collected into sterile containers, placed in a cool box $\left(4^{\circ} \mathrm{C}\right)$ and transported to the laboratory within 2 hours. The samples were then stored in a refrigerator and analysed within 8 hours of collection. Each sample was separated into two parts under sterile conditions; one part for urinalysis and the other for culture. The dip stick test was performed using urine test strips as described by the manufacturer (Condor-Teco, Beijing, China). Wet preparation of centrifuged urine was observed using 40 times objective lens to detect blood, pus and other cells. A calibrated $10 \mu \mathrm{l}$ wire loop was used to inoculate un- centrifuged urine into MacConkey, blood and Sabouraud's agar (BioMerieux, Marcy l'Etoile, France) and plates incubated aerobically at $37^{\circ} \mathrm{C}$ for 24 hours. Significant ASB was defined as urine culture of $>10^{5} \mathrm{cfu} / \mathrm{ml}$ without symptoms of cystitis. ${ }^{3}$ Isolates were identified using standard biochemical techniques. ${ }^{16}$

Antimicrobial susceptibility testing was done by the Kirby Bauer disk diffusion method using standard procedures. ${ }^{16}$ Disks of commonly used drugs against yeasts, Gram positive and negative organisms were selected. These included; nalidixic acid, nitrofurantoin, ceftriaxone, cefuroxime, doxycycline, ciprofloxacin, chloramphenicol, gentamicin, cefuroxime cotrimoxazole, vancomycin, doxycycline, oxacillin, erythromycin, augmentin, nystatin, ketoconazole, miconazole, flucytosine and fluconazole (Liofilchem, Roseto, Italy). The plates were incubated aerobically at $37^{\circ} \mathrm{C}$ for 18 hours after which the zones of inhibition were measured in milliliters and recorded as previously reported. ${ }^{4,5}$ Data were analyzed using SPSS Version 17.0 to measure differences between variables. Chisquare test was done to assess associations. P-values $<0.05$ were considered statistically significant.

\section{Results}

Of the 265 participants enrolled into the study 114 were males while 151 were females. Majority of participants were in the age group 50 years and above $(155,58.5 \%)$ while the least age range was less than 30 years $(18,6.8 \%)$. The overall prevalence of ASB in this study was 33.2\% (95\% CI; 27.6 - 39.3). There was a significant difference in the prevalence of ASB between diabetics and non-diabetics (38.3\% vs $26.1 \% ; \mathrm{P}=0.038)$. Table 1 shows the distribution of ASB with respect to age and sex. There was no significant difference in the distribution of ASB with age $(\mathrm{P}>0.05)$ among the study participants. However, women demonstrated a higher prevalence than men $(\mathrm{P}<0.001)$ in both diabetic and non-diabetic groups.

The distribution of urine isolates among study participants is presented on table 2 . There was a significant difference in the type of species isolated from diabetics and non-diabetics (18/19 vs 8/19; P $<0.001)$. The most prevalent organisms isolated were coagulase-negative staphylococci $(36.3 \%)$, Klebsiella sp $(15.9 \%)$, E. coli $(10.8 \%)$, Candida sp $(13.7 \%)$ and Serratia sp (10.8\%). Comparatively, Serratia sp and Candida sp were isolated frequently in diabetics than in non-diabetics $(\mathrm{P}<0.05)$ while Klebsiella sp was isolated more in non-diabetics $(\mathrm{P}<0.001)$. Generally, Gram negative rods were the most common type of organisms (45.1\%) isolated from urine, followed by Gram positive cocci $(41.2 \%)$ then yeasts $(13.7 \%)$. 
Table 1: Distribution of asymptomatic bacteriuria with respect to age and sex

\begin{tabular}{lllll}
\hline Age & $\begin{array}{l}\text { Diabetics with } \\
\text { ASB n (\%) }\end{array}$ & $\begin{array}{l}\text { Non-diabetics } \\
\text { with ASB n (\%) }\end{array}$ & $\begin{array}{l}\text { Total with } \\
\text { ASB n (\%) }\end{array}$ & N \\
\hline $16-30 \mathrm{yrs}$ & $4(22.2 \%)$ & $3(16.7 \%)$ & $7(38.9 \%)$ & 18 \\
$31-40 \mathrm{yrs}$ & $4(16.0 \%)$ & $3(12.0 \%)$ & $7(28.0 \%)$ & 25 \\
$41-50 \mathrm{yrs}$ & $15(22.4 \%)$ & $5(7.5 \%)$ & $20(29.9 \%)$ & 67 \\
$50+$ & $36(23.2 \%)$ & $18(11.6 \%)$ & $54(34.8 \%)$ & 155 \\
& $\mathbf{P}=\mathbf{0 . 8 8 5}$ & $\mathbf{P}=\mathbf{0 . 6 7 4}$ & $\mathbf{P}=\mathbf{0 . 7 7 9}$ & \\
Sex & & & & \\
Male & $8(7.0 \%)$ & $5(4.3 \%)$ & $13(11.3 \%)$ & 115 \\
Female & $51(34.0 \%)$ & $24(16.0 \%)$ & $75(50.0 \%)$ & 150 \\
& $\mathbf{P}<\mathbf{0 . 0 0 1}$ & $\mathbf{P}=\mathbf{0 . 0 0 3}$ & $\mathbf{P}<\mathbf{0 . 0 0 1}$ & \\
$\begin{array}{l}\text { Overall } \\
\text { prevalence }\end{array}$ & $\mathbf{5 9 / 1 5 4 ( 3 8 . 3 \% )}$ & $\mathbf{2 9 / 1 1 1}(\mathbf{2 6 . 1} \%)$ & $\mathbf{8 8 / 1 6 5 ( 3 3 . 2 \% )}$ & $\mathbf{1 6 5}$ \\
\hline
\end{tabular}

Table 2: Distribution of urine isolates among diabetics and non-diabetics

\begin{tabular}{|c|c|c|c|c|c|}
\hline Urine isolates & $\begin{array}{l}\text { Diabetics } \\
\text { n (\%) }\end{array}$ & $\begin{array}{l}\text { Non- } \\
\text { Diabetics } \\
\text { n }(\%)\end{array}$ & $\begin{array}{l}\text { Total } \\
\text { n (\%) }\end{array}$ & chi $^{2}$ Test & \\
\hline Candida sp & $12(16.7)$ & $2(6.7)$ & $14(13.7)$ & $\mathrm{P}=0.01$ & S \\
\hline Streptococcus sp & $4(5.6)$ & $0(0.0)$ & $4(3.9)$ & $\mathrm{P}>0.05$ & NS \\
\hline CNS & $24(33.3)$ & $13(43.3)$ & $37(36.3)$ & $\mathrm{P}>0.05$ & NS \\
\hline Staphylococcus aureus & $1(1.4)$ & $0(0.0)$ & $1(0.9)$ & $\mathrm{P}>0.05$ & NS \\
\hline Citrobacter freundii & $1(1.4)$ & $2(6.7)$ & $3(2.9)$ & $\mathrm{P}>0.05$ & NS \\
\hline E.coli & $9(12.5)$ & $2(6.7)$ & $11(10.8)$ & $\mathrm{P}>0.05$ & NS \\
\hline Pantoea sp & $2(2.8)$ & $0(0.0)$ & $2(2.0)$ & $\mathrm{P}>0.05$ & NS \\
\hline Proteus vulgaris & $0(0.0)$ & $1(3.3)$ & $1(0.9)$ & $\mathrm{P}>0.05$ & NS \\
\hline Enterobacter aerogenes & $2(2.8)$ & $0(0.0)$ & $2(2.0)$ & $\mathrm{P}>0.05$ & NS \\
\hline Klebsiella sp & $7(9.7)$ & $9(30.0)$ & $16(15.9)$ & $\mathrm{P}<0.001$ & S \\
\hline Serratia sp & $10(13.9)$ & $1(3.3)$ & $11(10.8)$ & $\mathrm{P}=0.03$ & S \\
\hline Total & 72 & 30 & 102 & & \\
\hline $\begin{array}{l}\text { No } \\
\text { isolated }\end{array}$ & $\begin{array}{l}18 / 19 \\
(94.7 \%)\end{array}$ & $\begin{array}{l}8 / 19 \\
(42.1 \%)\end{array}$ & $\begin{array}{l}19 \\
(100 \%)\end{array}$ & $P<0.001$ & $\mathbf{S}$ \\
\hline
\end{tabular}

$\mathrm{S}=$ Significant NS = Not significant. Percentages are calculated per column

Table 3: Antibiotic resistance of urinary E. coli and Klebsiella sp in diabetics and non-diabetics

\begin{tabular}{|c|c|c|c|c|c|}
\hline \multirow{3}{*}{$\begin{array}{l}\text { Antimicrobial } \\
\text { agent }\end{array}$} & \multicolumn{2}{|c|}{ Diabetics } & \multicolumn{2}{|c|}{ Non-diabetics } & \multirow[t]{3}{*}{ Pvalue } \\
\hline & E. coli & Klebsiella sp & E. coli & Klebsiella sp & \\
\hline & $\mathrm{n}(\%)$ & $\mathrm{n}(\%)$ & $\mathrm{n}(\%)$ & $\mathrm{n}(\%)$ & \\
\hline Nalidixic acid & $5(33.3)$ & $9(10.3)$ & $3(30.0)$ & $4(8.0)$ & NS \\
\hline Cefuroxime & $2(13.3)$ & $8(9.2)$ & $2(20.0)$ & $8(16.0)$ & NS \\
\hline Doxycycline & $2(13.3)$ & $8(9.2)$ & $1(10.0)$ & $3(6.0)$ & NS \\
\hline Nitrofurantoin & $0(0.0)$ & $11(12.6)$ & $0(0.0)$ & $9(18.0)$ & NS \\
\hline Ceftriaxone & $0(0.0)$ & $10(11.5)$ & $0(0.0)$ & $2(4.0)$ & NS \\
\hline Ciprofloxacin & $0(0.0)$ & $4(7.0)$ & $0(0.0)$ & $5(10.0)$ & NS \\
\hline Chloramphenicol & $0(0.0)$ & $12(13.8)$ & $0(0.0)$ & $8(16.0)$ & NS \\
\hline Erythromycin & $2(13.3)$ & $12(13.8)$ & $2(20.0)$ & $4(8.0)$ & NS \\
\hline Gentamicin & $4(26.7)$ & $13(14.9)$ & $2(20.0)$ & $7(14.0)$ & NS \\
\hline *Total & 15 & 87 & 10 & 50 & \\
\hline
\end{tabular}

P values on the table are between diabetics and non-diabetics; $N S=$ not significant. P value antibiotic resistance between $E$. coli and Klebsiella sp $>0.05 \quad *$ Total number of resistance observed within bacterial type 


\section{Discussion}

The association of diabetes mellitus and urinary tract infections is increasingly being reported. Asymptomatic bacteriuria is common among diabetic patients and may lead to serious complications if not properly managed. ${ }^{9}$ ASB has been identified as a risk factor for acquiring symptomatic UTIs especially in diabetic women ${ }^{1}$. UTIs are more severe in diabetic patients involving life-threatening complications such as emphysematous pyelonephritis and renal papillary necrosis? . Despite the importance of bacteriuria in diabetics; there is paucity of information on the relationship between UTI and diabetes especially in sub-Saharan Africa. Reports on the prevalence and aetiology of ASB appear contradictory especially in developing countries. Therefore, the present study was aimed to determine the prevalence and spectrum of microorganisms responsible for asymptomatic bacteriuria in diabetics and to determine antimicrobial resistance of urinary isolates.

The present study revealed an overall prevalence of ASB of $33.2 \% ; 38.3 \%$ in diabetics and $26.1 \%$ in non-diabetics (table 1). This result is concurrent with that of earlier reports which recorded prevalence of $36.2 \%$ in diabetics ${ }^{10}$ and $18.5 \%$ in non-diabetics. ${ }^{5}$ In Cameroon, high prevalence $(35.2-58.3 \%)$ of bacteriuria has been recorded. ${ }^{14,17}$ On the contrary, the prevalence of ASB in this study is higher than that of some studies which recorded $5.3-26 \%$ in diabetics and $3.5-15 \%$ in nondiabetics. $3,4,18,19,20$ Consequently, the issue of prevalence of ASB remains debatable. This inconsistency has been attributed to variations in sample size, geographical location, culture or screening method. ${ }^{11}$ In the present study, ASB was significantly higher in diabetics than non-diabetics $(\mathrm{P}$ $=0.038)$. This is in line with majority of previous reports. ${ }^{712}$ The prevalent microorganisms (Table 2) in the present study were coagulase negative Staphylococcus (36.3\%), Klebsiella sp (15.9\%), Candida sp $(13.7 \%)$, E. coli and Serratia sp (10.8\% each). This is contrary to other studies ${ }^{5,7,8,9}$ where E. coli was the predominant bacteria. The predominance of bacteria other than E. coli in the urinary tract is increasingly being reported. Recent study in Nigeria has reported Staphylococus aureus to be the most common uropathogen in diabetics and non-diabetics. ${ }^{12}$ The high prevalence of Staphylococus sp in ASB may be due to the fact that these organisms are mostly normal skin flora and can be introduced to the urinary tract during sexual intercourse. ${ }^{12}$ The high prevalence of CNS could also be attributed to inappropriate use of antibiotics which may encourage the proliferation of highly resistant bacteria such as CNS. ${ }^{21}$ The frequency of isolation of uropathogens (Table 2) was similar among diabetics and non-diabetics except for Candida sp and Serratia sp which were isolated more from diabetics than non-diabetics $(\mathrm{P}=0.01$ and $\mathrm{P}=0.03$, respectively). On the contrary, Klebsiella sp was isolated more from non-diabetics $(\mathrm{P}<0.001)$. The mechanism for this difference between diabetics and non-diabetics is not fully elucidated. However, higher carriage rate of Candida sp has also been reported in diabetics and this was attributed to the presence of excess glucose in diabetics that may encourage the growth of Candida sp. ${ }^{22}$

Results of the antibiotic susceptibility test revealed no significant difference $(\mathrm{P}>0.05)$ in the resistant pattern between diabetics and non-diabetics (Table 3). It was noted that nystatin; gentamicin and ciprofloxacin were the most active ingredients against yeasts, Gram positive and Gram negative organisms, respectively. Generally, high resistance was observed against oxacillin $(52.8 \%)$, cotrimoxazole $(64.7 \%)$, nitrofurantoin (46.5\%), Erythromycin (48.8\%) and gentamicin (59.3\%) Note: Gram negative bacteria only showed high resistance to gentamicin). The rate and spectrum of antibiotic resistance in this study is similar to that of studies conducted in other developing countries. ${ }^{3,4}$ In Cameroon, high rates of resistance have also been recorded among uropathogens and the results are similar to our findings. ${ }^{14,15}$ In one of such studies, resistance to all Gram negative isolates was observed for amoxicillin (87\%), piperacillin $(74 \%)$ and cotrimoxazole $(73 \%)$; meanwhile ofloxacine (88\%) and imipenem (98\%) were the most active antibiotics. ${ }^{15}$ Resistance to penicillins is associated with the production of beta lactamase. High resistance to cotrimoxazole may be due its frequent use in our study area to treat UTIs and other infectious diseases. In the present study, Gram negative bacteria showed high resistance to gentamicin (59.3\%) compared to Gram positive cocci $(11.8 \%)$. This difference in resistance may be due to the over-expression of efflux pumps in Gram negative bacteria. ${ }^{23}$ Nitrofurantoin resistance is usually uncommon; the moderate resistance observed in this study may be due to the development of crossresistance. Gram negative bacteria showed moderate to high resistance to both the second and third generation cephalosporins. This is commensurate to previous reports in the study are $\mathrm{a}^{15}$ as well as other 
developing countries. ${ }^{4}$ Resistance to ceftriaxone has been attributed to Extended spectrum beta lactamases (ESBLs) production. ${ }^{4}$ In the present study, E. coli strains demonstrated multi-drug resistance especially to gentamicin, nalidixic acid, doxycycline, cefuroxime and erythromycin. Multi-drug resistance of E. coli is a common phenomenon as reported by other authors. ${ }^{5,10,18}$ The most resistant Gram positive organisms were CNS. These bacteria have been reported to show high resistance to multiple antibiotics. $^{21}$ The $15 \%$ resistance of CNS to gentamicin and a corresponding $22.5 \%$ resistance to vancomycin observed in this study could be an indication of the circulation of gentamycinvancomycin resistant strains in the community. Infections with these strains are very difficult to treat and the consequences could be fatal. Interestingly, all S. aureus isolates were resistant to the glycopeptide vancomycin which is commonly used to treat severe infections caused by multi-resistant Gram positive cocci. Our results revealed that Candida sp were highly resistant to flucytosine. Resistance to this antimycotic is common; that is why flucytosine is mostly used in combination with an azole. ${ }^{24}$

\section{Conclusion}

The present study showed a high prevalence of ASB of $38.3 \%$ in diabetes mellitus patients against $26.1 \%$ in non-diabetics Southwest Cameroon. In addition, it reiterates the clinical significance of CNS and Candida sp in UTI. There was no significant difference in the resistant pattern between diabetics and nondiabetics. Ciprofloxacilin was the most effective antibiotic against most bacterial uropathogens.

\section{Recommendation}

The high prevalence of ASB and the multiple resistances of most isolates is a major concern that requires prompt action. Consequently, there is the need to enhance sensitization against antibiotic abuse so as to curb the spread of multi resistant uropathogens in the study area.

\section{Acknowledgement}

We would like to thank all the diabetic patients and healthy volunteers who consented to take part in this study. Our sincere gratitude also goes to the management and Staff of all the Hospitals where samples were collected. We also acknowledge the material and technical support of the Department of Microbiology and Parasitology, University of
Buea; where the study was conducted. The technical expertise of the statistician, Mr. Nana Celestin cannot be overemphasized. This study was funded by the University of Buea, Cameroon.

\section{References}

1. Geerlings SE, Stolk RP, Camps MJL, Netten PM, Collet TJ, Hoepelman AIM. Risk factors for symptomatic urinary tract infection in women with diabetes. Diabetes Care 2000a; 23: 1737-1741

2. Joshi N, Caputo GM, Weitekamp MR, Karchmer AW. Infections in patients with diabetes mellitus. NEnglJ Med 1999; 341: 19061912.

3. Alebiosu CO, Osinupebi OA, Olajubu FA. Significant asymptomatic bacteriuria among Nigerian type 2 diabetics. J Natl Med Assoc 2003; 95: 344-351.

4. Lyamuya EF, Moyo SJ, Komba EV, Haule M. Prevalence, antimicrobial resistance and associated risk factors for bacteriuria in diabetic women in Dar es Salaam, Tanzania. Afr J Microbiol Res 2011; 5 (6): 683-689.

5. Bonadio M, Costarelli S, Morelli G, Tartaglia T. The influence of diabetes mellitus on the spectrum of uropathogens and the antimicrobial resistance in elderly adult patients with urinary tract infection. BMC Infectious Diseases 2006; 6 (54): 1-7.

6. Manhal FS, Gauad SA. Asymptomatic bacteriuria in pregnant and diabetic women. $\mathrm{Al}$ Kindy Col Med J 2011; 7 (1): 39-46

7. Zamanzad B, Moiezzi M. Prevalence of asymptomatic bacteriuria and associated host factors in women with diabetes type 2. $J$ Res Health Sci 2006; 6 (1):14-20

8. Ishay A, Lavi I, Luboshitzky R. Prevalence and risk factors for asymptomatic bacteriuria in women with Type 2 diabetes mellitus. Diabet Med 2006; 23: 185-188.

9. Geerlings SE, Stolk RP, M. Camps MJL, Netten PM, Hoekstra JB, Bouter PK, et al. Asymptomatic bacteriuria may be considered a complication in women with diabetes. Diabetes Care 2000b; 23: 744-749.

10. Ophori EA, Imade P, Johnny EJ. Asymptomatic bacteriuria in patients with diabetes. J Bacteriol Research 2010; 2 (2): 14-17.

11. Assel MT, Al-Meer FM, Al-Kuwari MG, Ismail MF. Prevalence and predictor of asymptomatic bacteriuria among pregnant women attending 
Primary health care in Qatar Middle East J Fam Med 2009; 4:14-17.

12. Omoregie R, Erebor JO, Ahonkhai I, Isibor JO, Ogofere H. Observed changes in the prevalence of uropathogens in Benin City, Nigeria. NzJ Med Lab Science 2008; 29-31

13. Mbanya JC, Ngogang J, Salah JN, E. Minkoulou E, Balkau B. Prevalence of NIDDM and impaired glucose tolerance in a rural and urban population in Cameroon. Diabetologia 1997; 40: 824-829.

14. Akoachere JFT, Suylika Y, Njom HA, Esemu NS. Etiologic profile and antimicrobial susceptibility of community-acquired urinary tract infection in two Cameroonian towns. BMC Research notes 2012; 5: 219

15. Gangoue PJ, Koulla SS, Ngassam P, Adiogo D, Ndumbe P. Antimicrobial activity against Gram negative bacilli from Yaounde Central Hospital, Cameroon. African Health Sciences 2006; 6 (4): 232-235.

16. Clinical and Laboratory Standards, Wayne PA. Performance standards for antimicrobial disk susceptibility tests. Approved standard. Clinical and Laboratory Standards Institute 2006; ninth edition Document M2-A9.

17. Yuyun MF, Angwafo III FF, Koulla-Shiro S, Zoung-Kanyi J. Urinary tract infections and genitourinary abnormalities in Cameroonian men. Trop Med Int Health 2004; 9 (4): 520-525.
18. Hamdan HZ, Ziad AHM, Ali SK, and Adam I. Epidemiology of urinary tract infections and antibiotics sensitivity among pregnant women at Khartoum North Hospital. Annals Clin Microbiol Antimicrob 2011; 10(2).

19. Odetoyin WB, Aboderin AO, Ikem RT, Kolawole BA, Oyelese AO. Asymptomatic bacteriuria in patients with diabetes mellitus in Ile-Ife, South-West, Nigeria. East Afr Med J 2008; 85:18-23.

20. Wogu MD, Ogbebor NE. Prevalence of asymptomatic bacteriuria in secondary school students in Benin City. Afr Res Rev 2011; 5 (4): 145-151.

21. Kloos WE, Bannerman TL. Update on the clinical significance of coagulase-negative Staphylococci. Clin Microbiol Rev 1994; 7 (1): 117 140.

22. Al-Attas SA, Amro SO. Candidal colonization, strain diversity and antifungal susceptibility among adult diabetic patients. Annals of Saudi Medicine 2010; 30 (2): 101-108.

23. Li XZ, Livermore DM Nikaido H. Role of efflux pump(s) in intrinsic resistance of Pseudomonas aeruginosa resistance to tetracycline, chloramphenicol, and norfloxacin. Antimicrobial Agents and Chemotherapy 1994; 38: 1732-1741

24. Sheehan DJ, Hitchcock AC, Sibley CM. 1999. Current and emerging azole antifungal agents. Clin. Microbiol. Rev 1999; 12: 40-79. 